\title{
Mechanical strain effect of $n$-channel polycrystalline silicon thin-film transistors
}

\author{
C.-F. Huang, Y.-J. Yang, C.-Y. Peng, F. Yuan, and C. W. Liu ${ }^{\text {a) }}$ \\ Department of Electrical Engineering, National Taiwan University, Taipei, Taiwan 106, \\ Republic of China and Graduate Institute of Electronics Engineering, National Taiwan University, \\ Taipei, Taiwan 106, Republic of China
}

(Received 13 February 2006; accepted 10 July 2006; published online 5 September 2006)

\begin{abstract}
The current change of $n$-channel polycrystalline silicon thin-film transistors is analyzed experimentally and theoretically under different strain conditions. Under the uniaxial strain parallel to the channel, the $+6.7 \%$ and $+5.3 \%$ drain current enhancements are achieved in linear and saturation regions, respectively. There are $-4.4 \%$ (linear) and $-4.6 \%$ (saturation) drain current degradations when the uniaxial strain is applied perpendicular to the channel. The polycrystalline silicon is mainly composed of (111)-oriented grains, measured by electron diffraction pattern. Phonon-limited mobility is theoretically calculated. There is a qualitative agreement between experiments and theoretical analysis. (C) 2006 American Institute of Physics.
\end{abstract}

[DOI: $10.1063 / 1.2344855]$

Most display technology is based on amorphous Si thinfilm transistors (TFTs), but polycrystalline silicon (poly-Si) TFTs have attracted a great attention in recent years due to much higher carrier mobility. The low temperature polycrystalline silicon (LTPS) TFTs have much higher electron mobility $\left(\mu=100-300 \mathrm{~cm}^{2} / \mathrm{V} \mathrm{s}\right)$ and better reliability as compared to conventional amorphous Si TFTs $\left(\mu=1 \mathrm{~cm}^{2} / \mathrm{V} \mathrm{s}\right)$. Strained-Si technology has been used extensively in the $\mathrm{Si}$ industry for $90 \mathrm{~nm}$ and beyond. The mechanical strain effects on complementary metal-oxide semiconductor and optical devices have been reported. ${ }^{1-7}$ However, no strain effect on poly-Si TFTs was reported in the past. The electrical performance of poly-Si TFTs is investigated under different strain conditions.

The LTPS poly-Si TFTs are fabricated with top-gated structure. ${ }^{8}$ The amorphous Si layer is deposited using radio frequency plasma-enhanced chemical vapor deposition system, and excimer laser crystallization technique is used to form poly-Si film with a grain size of $\sim 0.3 \mu \mathrm{m}$. The transistor is fabricated after gate patterning and source/drain formation. The effective oxide thickness is $100 \mathrm{~nm}$. The effective electron mobility of poly-Si TFTs is $\sim 125 \mathrm{~cm}^{2} / \mathrm{V} \mathrm{s}$. The mobility is extracted by using the conventional square law current model from the $I_{\mathrm{DS}}-V_{\mathrm{DS}}$ curve. The extracted mobility is comparable to the value in the literatures. ${ }^{9,10}$ The estimated gate-channel capacitance $C_{\mathrm{gc}}(\sim 0.07 \mathrm{pF})$ is beyond the measurement limit of our meter due to the small area. Therefore, the split capacitance-voltage technique used in the strained-Si field effect transistors cannot be conducted in this case.

The mechanical setup to apply external strain was reported previously. ${ }^{11,12}$ For single crystalline $\mathrm{Si}$, the level of external strain was measured by Raman spectroscopy and was consistent with finite element simulation by ANSYS. ${ }^{13}$ The poly-Si has a built-in tensile stress of $\sim 1 \mathrm{GPa}$ $(\sim 0.44 \%),{ }^{14}$ measured by the Raman shift of $6.5 \mathrm{~cm}^{-1}$ as compared to bulk Si. The apparent strains are calculated to

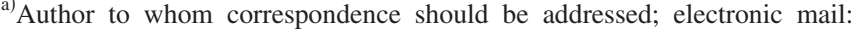
chee@cc.ee.ntu.edu.tw
}

be $\sim 0.15 \%$ and $\sim 0.17 \%$ for uniaxial and biaxial strains, respectively, by the finite element method. However, the poly-Si film is in elastic strain as grown, and the wafer possesses curvature even before bending. Therefore, it may be difficult to quantify the strain level using Raman.

Figure 1 shows the drain current $\left(I_{\mathrm{DS}}\right)$ versus drain voltage $\left(V_{\mathrm{DS}}\right)$ of $n$-channel TFTs. The gate width and length are 20 and $10 \mu \mathrm{m}$, respectively. The drain currents under uniaxial tensile strain have $+6.7 \%$ and $+5.3 \%$ enhancements in the linear region and saturation region, respectively, for the strain parallel to the channel (longitudinal strain). However, the drain currents are degraded $-4.4 \%$ and $-4.6 \%$ for linear region and saturation region, respectively, for the uniaxial tensile strain perpendicular to the channel (transverse strain). For the linear region, the drain current change is measured at $V_{\mathrm{GS}} V_{\mathrm{TH}}=10 \mathrm{~V}$ and $V_{\mathrm{DS}}=5 \mathrm{~V}$, and for the saturation region, current change is measured at $V_{\mathrm{DS}}=10 \mathrm{~V}$.

The drain current change under various strain conditions is shown in Fig. 2. As longitudinal strain is applied, the drain current increases with increasing strain, whereas the drain current degraded gradually with increasing transverse strain. However, the current change is within $1 \%$ for the external biaxial strain. The sensitivity of drain current to strain $(\varepsilon)$ is defined as $S_{\varepsilon}\left(I_{\mathrm{DS}}\right)=\Delta I_{\mathrm{DS}} / \varepsilon I_{\mathrm{DS}}$. The $S_{\varepsilon}\left(I_{\mathrm{DS}}\right)=35$ and -31 for longitudinal strain and transverse strain, respectively. The $S_{\varepsilon}$ $\left(I_{\mathrm{DS}}\right)$ is much higher than previously reported values of amorphous TFTs. ${ }^{15}$

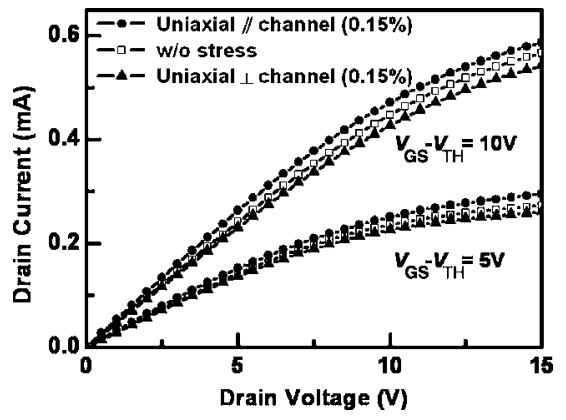

FIG. 1. Output characteristics of poly-Si TFTs under uniaxial tensile strain. 


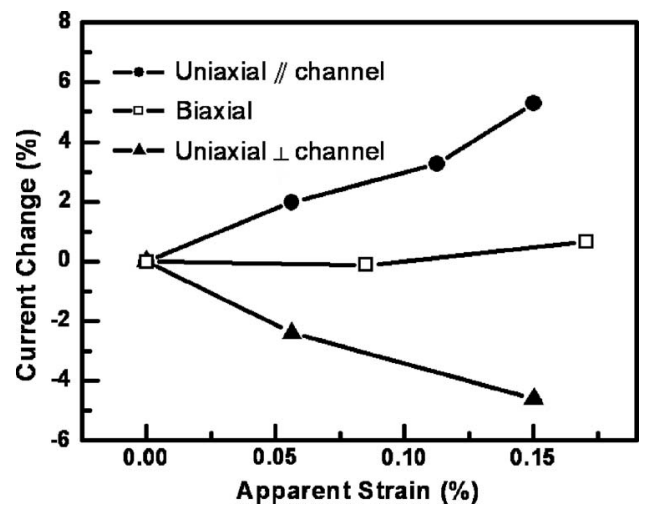

FIG. 2. Drain current change vs various apparent strains. The apparent strain is the strain calculated by finite element method.

The electron diffraction pattern of transmission electron microscopy (TEM) is used to investigate the crystal orientation of the poly-Si film on glass. The plane view TEM image is shown in Fig. 3. From the electron diffraction pattern of poly-Si grain (the inset of Fig. 3), the poly-Si film is mainly composed of (111)-oriented grains, ${ }^{16}$ which is consistent with the powder x-ray diffraction (not shown).

The phonon-limited electron mobility in the single crystalline Si under biaxial/uniaxial strain on (001), (110), and (111) grains is theoretically calculated. ${ }^{17,18}$ The accuracy of our theoretical calculation is calibrated with the previous work of the strained-Si field effect transistors, ${ }^{6,19}$ and gives the reasonable estimation of mobility data. ${ }^{7,11,12}$ The calculated mobility changes due to external biaxial/uniaxial strain on various grain orientations are shown in Table I. The built-in biaxial strain in the poly-Si film is considered in the calculation, and the mobility change in the table is solely due to the external mechanical strain. For the channel length of $10 \mu \mathrm{m}$ with the grain size of $\sim 0.3 \mu \mathrm{m}$, the electron travels many (111) grains with different in-plane direction. Therefore, the average mobility over all possible grain directions has to be considered. For (111) grain orientation, the average mobility has $9.5 \%$ enhancement for longitudinal strain, but has $-11.7 \%$ degradation for transverse strain. The trend is consistent with experimental data $(5.3 \%$ for longitudinal strain and $-4.6 \%$ for transverse strain), but the absolute mag-

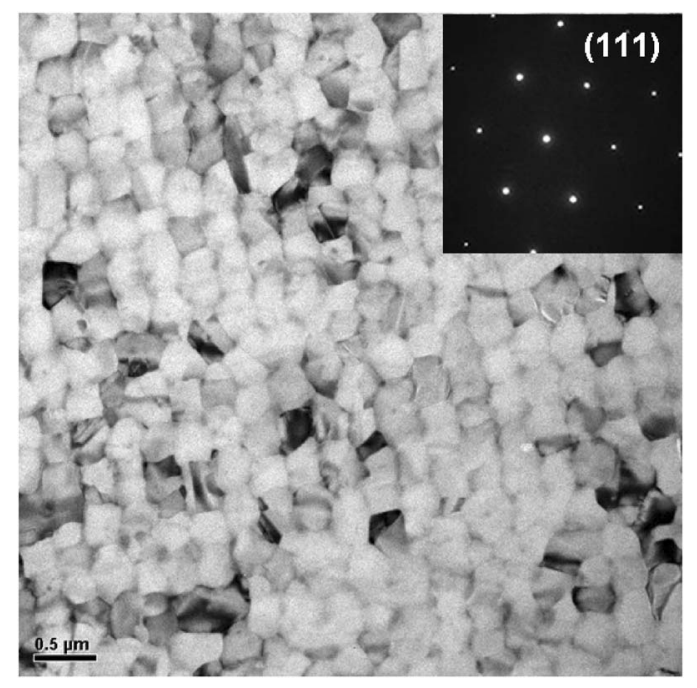

FIG. 3. Plane view TEM image of poly-Si film. The electron diffraction pattern shows that the film is mainly composed of (111)-oriented grains. lower energy valley under uniaxial strain (shaded area).
Downloaded 13 Feb 2009 to 140.112 .113 .225 . Redistribution subject to AIP license or copyright; see http://apl.aip.org/ap
TABLE I. Mobility change (\%) of single crystalline Si under tensile stress. The built-in stress of $\sim 1 \mathrm{GPa}$ in poly-Si film is considered in the calculation, and the mobility change is due to the external mechanical strain. The average mobility is the mean value for all possible channel directions.

\begin{tabular}{|c|c|c|c|c|}
\hline $\begin{array}{c}\text { Grain } \\
\text { orientation }\end{array}$ & $\begin{array}{l}\text { Channel } \\
\text { direction }\end{array}$ & $\begin{array}{c}\text { Uniaxial ॥ } \\
(0.15 \%)\end{array}$ & $\begin{array}{c}\text { Uniaxial } \perp \\
(0.15 \%)\end{array}$ & $\begin{array}{c}\text { Biaxial } \\
(0.17 \%)\end{array}$ \\
\hline \multirow{3}{*}{ (001) } & {$\left[\begin{array}{lll}1 & 0 & 0\end{array}\right]$} & 3.0 & 2.7 & 6.0 \\
\hline & {$\left[\begin{array}{lll}1 & 1 & 0\end{array}\right]$} & 3.7 & 3.7 & 6.0 \\
\hline & Average & 3.3 & 3.2 & 6.0 \\
\hline \multirow{3}{*}{ (110) } & {$\left[\begin{array}{lll}0 & 0 & \overline{1}\end{array}\right]$} & 6.5 & -4.4 & 4.9 \\
\hline & {$\left[\begin{array}{lll}\overline{1} & 1 & 0\end{array}\right]$} & 0.9 & 2.8 & 3.7 \\
\hline & Average & 2.6 & 0.4 & 4.8 \\
\hline \multirow{3}{*}{ (111) } & {$\left[\begin{array}{lll}1 & 1 & \overline{2}\end{array}\right]$} & 9.2 & -12.2 & 0.0 \\
\hline & {$\left[\begin{array}{lll}\overline{1} & 1 & 0\end{array}\right]$} & 10.6 & -9.6 & 0.0 \\
\hline & Average & 9.5 & -11.7 & 0.0 \\
\hline
\end{tabular}

nitude is lower. The reason for the deviation from the model is unclear. The discrepancy between the data and the calculation might be attributed to the existence of a small fraction of other grains besides (111). The theoretical average mobility of (001) and (110) grain orientations shows a completely different trend with our data, indicating that the grain orientation in the poly-Si film is mainly (111) oriented and is consistent with the electron diffraction pattern and $\mathrm{x}$-ray diffraction.

The channel direction is along $\langle 11 \overline{2}\rangle$ as an example to explain the mechanism of mobility change due to strain [Fig. 4(a)]. For the longitudinal strain [Fig. 4(b)], valleys 1 and 2 shift to higher energy level than other valleys. Most electrons are populated in the lower energy valleys (shaded area). Therefore, the lighter effective mass of the lower energy valleys is responsible for the mobility enhancement. However, for the transverse strain [Fig. 4(c)], most electrons locate in valleys 1 and 2 due to their lower energy levels, and the heavier effective mass along $\langle 11 \overline{2}\rangle$ leads to mobility degradation. ${ }^{3,18}$ The average mobility over all possible directions should be calculated due to the different grains along the channel.

The strain effect of $n$-channel poly-Si TFTs is investigated. The electrical performance can be further enhanced with external mechanical strain. The low cost and reasonable performance enhancement by the external mechanical bending is beneficial for the future flat panel display technology.

The National Taiwan University group is supported by the National Science Council of Taiwan under Contract No.
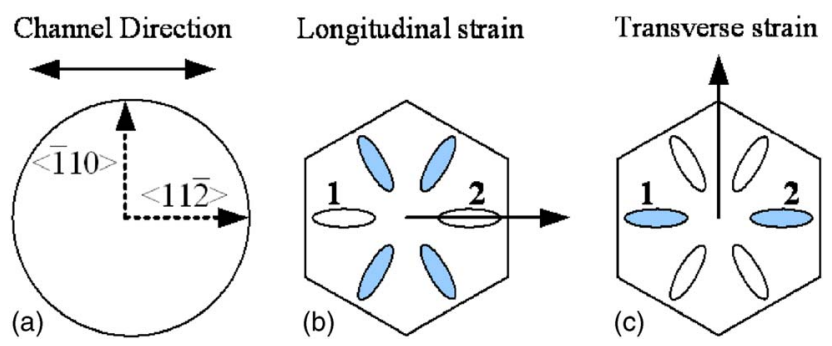

FIG. 4. (a) Two specific channel directions of (111)-oriented Si. The projection of constant-energy contour of (111) Si conduction band under (b) longitudinal strain and (c) transverse strain. Most electrons locate in the

lower energy valley under uniaxial strain (shaded area).
to AIP license or copyright; see http://apl.aip.org/apl/copyright.jsp 
NSC 94-2215-E-002-040. The authors would like to thank S. T. Chang (National Chung Hsing University, Taiwan, R.O.C.) for the helpful discussion. The fabrication of chip by Toppoly Optoelectronics Corp., Taiwan, is highly appreciated.

${ }^{1}$ S. E. Thompson, G. Sun, K. Wu, J. Lim, and T. Nishida, Tech. Dig. - Int. Electron Devices Meet. 2004, 221.

${ }^{2}$ S. Maikap, C.-Y. Yu, S.-R. Jan, M. H. Lee, and C. W. Liu, IEEE Electron Device Lett. 25, 40 (2004).

${ }^{3}$ C. W. Liu, S. Maikap, and C.-Y. Yu, IEEE Circuits Devices Mag. 21, 21 (2005).

${ }^{4}$ F. Yuan, S.-R. Jan, S. Maikap, Y.-H. Liu, C.-S. Liang, and C. W. Liu, IEEE Electron Device Lett. 25, 483 (2004).

${ }^{5}$ F. Yuan, C.-F. Huang, M.-H. Yu, and C. W. Liu, IEEE Trans. Electron Devices 53, 724 (2006).

${ }^{6}$ H. Irie, K. Kita, K. Kyuno, and A. Toriumi, Tech. Dig. - Int. Electron Devices Meet. 2004, 225.

${ }^{7}$ S. Maikap, M. H. Liao, F. Yuan, M. H. Lee, C.-F. Huang, S. T. Chang, and C. W. Liu, Tech. Dig. - Int. Electron Devices Meet. 2004, 233.

${ }^{8}$ K. Tanaka, H. Arai, and S. Kohda, IEEE Electron Device Lett. 9, 23 (1988).
${ }^{9}$ K. C. Moon, J.-H. Lee, and M.-K. Han, IEEE Trans. Electron Devices 52, $512(2005)$

${ }^{10}$ S.-M. Han, M.-C. Lee, M.-Y. Shin, J.-H. Park, and M.-K. Han, Proc. IEEE 93, 1297 (2005)

${ }^{11}$ M. H. Liao, M. J. Chen, T. C. Chen, P. L. Wang, and C. W. Liu, Appl. Phys. Lett. 86, 223502 (2005).

${ }^{12}$ M. H. Liao, S. T. Chang, M. H. Lee, S. Maikap, and C. W. Liu, J. Appl. Phys. 98, 066104 (2005).

${ }^{13}$ M. H. Liao, C.-Y. Yu, C.-F. Huang, C.-H. Lin, C.-J. Lee, M.-H. Yu, S. T. Chang, C.-Y. Liang, C.-Y. Lee, T.-H. Guo, C.-C. Chang, and C. W. Liu, Tech. Dig. - Int. Electron Devices Meet. 2005, 1023.

${ }^{14}$ P. Lengsfeld, N. H. Nickel, Ch. Genzel, and W. Fuhs, J. Appl. Phys. 91, 9128 (2002).

${ }^{15}$ P. Servati and A. Nathan, Proc. IEEE 93, 1257 (2005).

${ }^{16}$ S. Christiansen, P. Lengsfeld, J. Krinke, M. Nerding, N. H. Nickel, and H. P. Strunk, J. Appl. Phys. 89, 5348 (2001).

${ }^{17}$ S. Takagi, Judy L. Hoyt, Jeffrey J. Welser, and James F. Gibbons, J. Appl. Phys. 80, 1567 (1996).

${ }^{18}$ I.-J. Yang, C.-Y. Peng, S. T. Chang, and C. W. Liu, International Semiconductor Device Research Symposium, 2005 p. 187.

${ }^{19}$ K. Uchida, T. Krishnamohan, K. C. Saraswat, and Y. Nishi, Tech. Dig. Int. Electron Devices Meet. 2005, 135. 